\title{
SOBRE OS PALEOAMBIENTES DEPOSICIONAIS DO GRUPO PASSA DOIS
}

\author{
Josué Camargo MENDES*
}

\begin{abstract}
RESUMO
O presente artigo consiste, maiormente, num ensaio de revisão crítica dos paleoambientes deposicionais do Grupo Passa Dois com base em novos achados dos paleontológicos e consideração do espectro de estruturas sedimentares conhecidas e dos dados geoquímicos disponíveis. Embora chamando a atenção para o risco das inferências numa situação de escassez de dados, como a presente, julga o autor aceitáveis condições parálicas para a sedimentação que gerou a Formação Irati, extensivas à gênese das formações Corumbataí (Estado de São Paulo) e Estrada Nova (Estados do Paraná, Santa Catarina e Rio Grande do Sul). Alude, também, ao problema das delimitações estratigráficas inferior e superior do grupo em apreço e ao problema da conceituação das suas subdivisões.
\end{abstract}

\section{ABSTRACT}

This paper deals mainly with a critical revision of the paleoenvironments of sedimentation of the Brazilian Paraná Basin Permo-Carboniferous known as Passa Dois Group. This revision is based on new paleontological discoveries as well as sedimentary structure evaluation and available geochemical data. The author calls attention on the risks of inferences based on scarce data; however, he judges as reasonable the interpretation of paralic conditions for the sedimentary environments for the Irati Formation considering similar conditions for the sedimentary environment of Corumbatai (States of S. Paulo and Estrada Nova (State of Paraná), Santa Catarina and Rio Grande do Sul) formations.

It is discussed here as well the problem of stratigraphical delimitations of this group and its subdivisions.

\section{LIMITES ESTRATIGRÁFICOS INFERIOR E SUPERIOR DO GRUPO PASSA DOIS}

O presente artigo objetiva enfocar os problemas referentes aos paleoambientes deposicionais do Grupo Passa Dois. À guisa de preâmbulo, abordaremos, contudo, alguns tópicos de caráter estratigráfico.

Começaremos com um enfoque sobre, o problema dos contatos basal e superior do grupo em questão.

Os autores são unânimes em considerar que o contato do Grupo Passa Dois com o Grupo Tubarão é de natureza concordante e, quase invariavelmente, o situam no limite entre a Formação Palermo e a Formação Irati.

Segundo SCHNEIDER et alii (1974) o contato em apreço corresponde à base do Membro Taquaral, unidade que incluem no Irati e que consideram onipresente na bacia do Paraná. Mas, na representação diagramática da coluna estratigráfica dessa bacia omitem-no no Rio Grande do Sul, Mato Grosso e Goiás. Em São Paulo ele parece, também, não ser contínuo, a julgar pelas informações contidas no "Léxico Estratigráfico" organizado por MEZZALIRA et alii (1981).

A continuiidade da Formação Palermo é igualmente discutível, pois, no consenso geral, tanto o Palermo como o Rio Bonito são substituídos, em São Paulo, pela Formação Tatuí.

Maior é o problema referente ao contato superior do grupo.

Embora para a maioria dos autores ele

* Prof. titular aposentado do Instituto de Geociências, Rua Japão, 85 - apto. 171 - 04530 São Paulo - Si Brasil 
corresponda a uma desconformidade, no Rio Grande do Sul há controvérsia sobre esse fato. Ali o Grupo Passa Dois é sucedido pelo Grupo Rosário do Sul de idade triássica.

Gamermann, ao introduzir a denominação Rosário do Sul, em 1973, referiu esse contato como transicional. No ano seguinte, BORTOLUZZI (1974) manifestou-se a respeito do contato em apreço que, no seu entender, era discordante. Essa opinião foi endossada por ANDREIS et alii (1980) no trabalho em que propuseram a elevação do Rosário do Sul à categoria de grupo, em 1980 .

Mais recentemente, porém, BARBERENA et alii (1983), passando em revista o conhecimento sobre os tetrápodes permianos e triássicos da bacia do Paraná, aludiram à inexistência de uma quebra importante entre o Rosário do Sul e o Estrada Nova. Aparentemente, o argumento paleontológico deve ter influido muito nessa tomada de posição. Os pareiassauros da parte superior do Estrada Nova do Rio Grande do Sul correspondem, segundo BARBERENA et alii (op. cit.), à Zona Daptocephalus do Karroo, ou seja, a níveis muito elevados do Permiano Superior. Como naquele Estado sucede ao Estrada Nova a unidade basal do Grupo Rosário, que é a Formação Sanga do Cabral, datada como triássica inferior com base nos répteis, torna-se razoável supor uma passagem gradativa entre aquelas duas formações.

PETRI \& FÚLFARO (1983) foram um pouco mais longe, julgando possível que a sedimentação do Rio do Rasto, tenha persistido até o início do Triássico. Lvocam a favor dessa hipótese três pontos principais: $1 .^{\circ}$ ) a idade permiana superior dos tetrápodes do Rio do Rasto; $2 .^{\circ}$ ) a não ocorrência desta formação junto com o Rosário do Sul ou Pirambóia; $3 .^{\circ}$ ) a datação radiométrica da mesma que forneceu $228 \pm 9$ milhões de anos, valor praticamente coincidente com o início do Triássico.

Esses argumentos merecem um pequeno comentário.

Mais novos que os tetrápodes do Rio do Rasto do Paraná, a que aludem aqueles autores, são os pareiassauros do Estrada Nova do Rio Grande do Sul, embora referíveis, também, ao Permiano Superior. Esse fato só veio a público, aliás, depois da publicação da citada obra de Petri e Fúlfaro. Quanto à idade radiométrica, o método do rubídioestrôncio of erece, no caso de sedimentos, valores mais seguramente relacionados com a idade diagenética do que com a fase deposicional, podendo ocorrer um grande intervalo entre as duas. Por outro lado, o valor do limite entre o Permiano e o Triássico varia de tabela para tabela; assim, enquanto EYSINGA (1978), o estima em 230 milhões, outros o sobem a 242 milhões ou o baixam para 225 milhões.

\section{PROBLEMA DOS CONTATOS ENTRE AS SUBDIVISÕES DO GRUPO PASSA DOIS}

Em princípio, as subdivisões estratigráficas em uso do Grupo Passa Dois deveriam corresponder a unidades litoestratigráficas: Fosse esse o caso, teriam que possuir limites de fácil reconhecimento, deveriam ser mapeáveis e a sua extensão lateral estaria na dependência de uma comprovada continuidade física com preservação das características diagnósticas.

Feitas essas considerações, vejamos se elas se comprovam no caso.

Em um alentado trabalho sobre o Irati do Estado de São Paulo, MEZZALIRA (1971) chamou a atenção para a dificuldade encontrada na determinação do contato entre essa unidade e o Serra Alta. "Nas sondagens", escreve o autor, “essa distinção é mais imprecisa, pois os siltitos cinzentos da denominada fácies Paranapanema são mais escuros, como em Porangaba, e se confundem com os da mesma cor da Formação Irati que se situam logo abaixo, sem discordância. Essa distinção", esclarece ele, "é feita, na maioria das vezes, pelo odor fétido que a rocha apresenta e que é característica do Irati'’.

“Na parte nordeste do Estado", prossegue Mezzalira, "'a tonalidade, e a própria litologia, diferem das comuns, encontradas na parte mais central da bacia o que torna mais difícil o seu reconhecimento."

LANDIM \& FÚLFARO (1972) em um artigo dedicado à análise da superfície de tendência dos dados de espessura do Carbonífero e Permiano da bacia do $\mathrm{Pa}$ raná, referem-se, de passagem, à faciologia do Grupo Passa Dois. Para eles, as 
unidades do mesmo representam fácies heterópicas de um grande complexo sedimentar e a dificuldade no entendimento dessa interrelação de fácies seria a causa da rígida classificação estratigráfica em adoção. A simples observação do bloco-diagrama em que esses autores representaram a sua interpretação teórica sobre o comportamento espacial das fácies sedimentares do Passa Dois dispensa maiores considerações.

SCHNEIDER et alii (1974) aludem ao fato de que as oscilações no nível das águas ocasionaram recorrências do Serra Alta na parte basal da Formação Teresina.

A concepção de GAMA Jr. (1979) sobre a estratigrafia e gênese do Grupo Passa Dois diverge da dos demais autores. Limitar-nos-emos, entretanto, apenas a citar algumas das considerações feitas nesse trabalho que são de interesse para o presente contexto. Adverte o seu autor que as unidades formais do Passa Dois reúnem sedimentos de uma mesma ou de províncias geomórficas adjacentes. A não compreensão desse fato, parece-lhe ter sido o motivo maior das controvérsias sobre ambientes de sedimentação, uma vez que, ao se restringir uma análise paleoambiental a linhas ou superfícies artificiais, seciona-se a sucessão vertical natural de fácies que reflete a distribuição horizontal dos ambientes. Para ele, a fácies Teresina, restrita, no mencionado trabalho, aos lamitos cinzentos da unidade homônima, recorre no Membro Serrinha e a fácies característica deste também comparece sob a forma de intercalações na Formação Teresina e, finalmente, a fácies de lamitos vermelhos Morro Pelado ocorre, igualmente, na parte superior do Membro Serrinha.

PETRI \& COIMBRA (1982), também se referem à interdigitação do Serra Alta com o Irati.

$\mathrm{Na}$ Geologia do Brasil de PETRI \& FÚLFARO (1983) não só se menciona que o Serra Alta se interdigita com o Irati, como se define o Estrada Nova como composto de duas fácies interdigitantes: Teresina e Serrinha.

Em 1980, BARBERENA et alii apresentaram uma bioestratigrafia tentativa da seqüência do Morro Pelado aflorante na serra do Cadeado, Estado do Paraná, com base na distribuição vertical de três gêneros de tetrápodes. A presença de restos de Endothiodon, um réptil do grupo dos dicinodontes, antes conhecido somente no Permiano Superior da África, levou-os a estabelecer uma correlação entre a fauna em apreço e a da Zona Cistecephalus da Série Beaufort Inferior. Três anos mais tarde, BARBERENA et alii (1983) comunicaram no $8 .^{\circ}$ Congresso Brasileiro de Paleontologia que os níveis de pareiassauros encontrados na fácies Armada do Rio Grande do $\mathrm{Sul}$ correspondiam à Z on a Daptocephalus da mesma Série Beaufort, porém de posição estratigráfica mais elevada que a outra zona mencionada. Assim, de acordo com os autores da comunicação, os níveis de tetrápodes da serra do Cadeado seriam mais antigos que os de pareiassauros do Rio Grande do Sul, embora caindo ambos dentro da amplitude do Tatariano. A fácies Armada tem sido situada na parte superior da Formação Estrada Nova, conquanto apresente características litológicas evocativas do Membro Serrinha (PETRI \& FÚLFARO, 1983). Mesmo supondo-se tal correspondência, os níveis do Morro Pelado da serra do Cadeado seriam cronologicamente, mais antigos que os do Serrinha sul-rio-grandense.

Divergem os autores a respeito da posição geográfica do contato entre as formações Estrada Nova e Corumbataí. Alguns o recuam bem para o interior do Estado de São Paulo; outros o traçam pelos limites políticos entre São Paulo e Paraná. Aliás, questiona-se, por vezes, a manutenção da Formação Corumbataí. BRITO (1982), por exemplo, clama que essa formação mostra características similares às da Formação Estrada Nova, pelo que lhe parece injustificável essa denominação.

Como se vê, os contatos entre as unidades do Grupo Passa Dois, além de subjetivos, não se configuram como superfícies ideais estendíveis de norte a sul e de leste a oeste. E a bioestratigrafia baseada nos tetrápodes mostra que uma mesma superfície isócrona corta diferentes unidades litoestratigráficas que, teoricamente, deveriam sobrepor-se.

\section{FÓSSEIS E PALEOAMBIENTE}

Passemos ao objetivo principal do artigo que é o dos paleoambientes do Grupo Passa Dois. 
Como o espaço não nos permite uma longa análise do conteúdo paleontológico dessa unidade, selecionaremos alguns dos tópicos ligados a esse documentário que oferecem interesse particular para aquele objetivo. Aproveitaremos, entretanto, a oportunidade, para elogiar e encarecer o trabalho dos nossos colegas, especialmente do Rio Grande do Sul e de São Paulo que vêm ampliando significativamente, o conhecimento paleozoológico e paleobotânico sobre a unidade em apreço.

Em 1978, FÚlfFARO et alii comunicaram no $30{ }^{\circ}$ Congresso Brasileiro de Geologia a descoberta de foraminiferos aglutinados na Formação Corumbataí. Foram eles obtidos em calcários atravessados em uma sondagem executada em Laras, Municipio de Laranjal Paulista, Estado de São Paulo. No resumo referente à comunicação faltam dados quanto à posição precisa desses fósseis e estes ainda aguardam descrição.

Há poucos meses, Vilma Alves Campanha noticiou, numa sessão da Academia Brasileira de Ciências, o achado de diversos espécimes de lingulideos em um nivel de folhelho do Irati. A amostra que os contêm procede de um poço localizado em Amadeu Amaral, Municipio de Marilia. Informou Campanha que se associam aos braquiópodes, foraminiferos bentônicos aglutinados atribuiveis aos gêneros Ammodiscus e Sorosphaera e ostracódeos do gênero Bairdia. Os braquiópodes foram classificados, a título provisório, como Lingula sp. Com base nos parâmetros paleoecológicos inferidos desses fósseis a autora julgou provável que o paleoambiente deposicional do Irati tenha sido lagunar. A referida paleontóloga comunicou-nos, verbalmente, o registro do gênero Botryococcus em folhelhos da base do Irati da área de Cuiabá Paulista Estado de São Paulo. Esse fato vem corroborar a inferência de um ambiente misto, pois, como se sabe, Botryococcus vive tanto em águas doces como em águas salobras, mas não em ambientes euhalinos.

Inquestionavelmente, a presença de braquiópodes e de foraminiferos assegura uma ligação da bacia deposicional do Passa Dois com o mar ao nivel das formaçôes em que ocorrem.

Cumpre lembrar, ainda, no tocante ao problema paleoambiental da Estrada
Nova, os seguintes elementos: a intolerância das carófitas e dos conchostráceos para com as condições de salinidade normal e a composição endêmica da malacofauna.

Devemos, ainda, a Vilma Campanha, a informação verbal sobre o achado, em amostras de sondagem de ostracódeos de hábito mixo-halino, pertencentes aos gêneros Microcheillinela e Carbonita, na base do Serrinha e de ostracódeos de hábito dulcaqüícola na parte superior do mesmo. Destes os mais freqüentes pertencem ao gênero Candona. Trata-se de material obtido em sondagem realizada na região do rio Ivaí, Estado do Paraná.

O paleoambiente do Rio do Rasto, aqui entendido como um sinônimo de Morro Pelado, não constitui objeto de polêmica entre os autores pelo que os seus fósseis dispensam considerações especiais.

\section{ESTRUTURAS SEDIMENTARES}

Em suma, os poucos dados paleontológicos disponiveis de significação paleoambiental não garantem mais do que um ambiente mixo-halino para o Irati e para o Estrada Nova. O problema da determinação da ou das modalidades desse ambiente fica, pois, na dependência de outros elementos.

Até que ponto as estruturas sedimentares poderiam auxiliar na solução desse problema?

PETRI \& COIMBRA (1982) tendem à aceitação de um ambiente lagunar hipersalino para a Formação Irati, evocando em abono desse posicionamento o caráter redutor inferivel dos folhelhos, a ausência de fósseis marinhos típicos e as evidências de oscilações ambientais relativas tanto à oxigenação, como à salinidade. Tais evidências advieram da observação das estruturas sedimentares e da presença de evaporitos constatados em sondagem.

As estruturas sedimentares consideradas mais expressivas em relação ao contexto foram as fendas de dessecação e as estruturas em tepee. As primeiras indicam exposição subaérea do sedimento em que se formaram. MEZZALIRA (1971) já as registrara em amostras de sondagem. 
No citado artigo de Petri e Coimbra a presença das estruturas em tepee é considerada como um forte apoio à idéia de um paleoambiente lagunar por serem elas encontradiças em planícies de maré. ASSERETO \& KENDAL (1977), autores de um excelente apanhado a respeito de estrutura em tepee recentes e antigas, associam-nas a climas áridos e semiáridos, fato que parece harmonizar-se, até certo ponto, com a faciologia do Irati, tendo-se em vista o encontro de evaporitos.

Sentimo-nos tentados, nestas alturas, a comentar o modelo paleolagunar atribuído ao Irati. Se por um lado ele se afigura o mais compatível com os parâmetros disponíveis, por outro cria um grande problema de escala, mesmo que se considere um sistema de lagunas em vez de uma só.

A única estrutura sedimentar primária sempre mencionada com relação ao Serra Alta é a estratificação paralela horizontal, aliás pouco comum. Sozinha não tem grande valor para a distinção de ambientes; geralmente forma-se abaixo do nível de base das ondas, mas ocorre tanto em sedimentos marinhos como lagunares ou lacustres. Muitíssimo mais difundida é a aparente estrutura maciça dos siltitos Serra Alta, cuja origem ainda não despertou grande curiosidade.

SCHNEIDER et alii (1974) citam as seguintes estruturas sedimentares do Teresina: marcas onduladas, microestratificação cruzada, estratificação ondulada, estrutura flaser e fendas de dessecação. Chamam a atenção, ainda, para a associação das mesmas com bancos de coquinas e calcários oolíticos. Na sua opinião essas estruturas indicam ambientes dos tipos inframaré, intermarés e supramaré.

Com efeito, tais estruturas são comuns em planícies de maré, conquanto não privativas delas. Nisso se inclui a estratificação do tipo flaser. Os oólitos e os estromatólitos também se formam em lagos. Faltou a menção à estratificação em espinha-de-peixe, freqüente nos depósitos de canais de maré, embora não exclusiva, como as demais, das planícies de maré. No Teresina ela parece ser rara.

As pedreiras de calcário de Itaguaí, Estado de São Paulo, oferecem um rico elenco de estruturas sedimentares que SUGUIO et alii descreveram em 1974 e que PETRI \& COIMBRA (1982) reestudaram no trabalho há pouco mencionado. As rochas ali aflorantes têm sido referidas à Formação Estrada Nova, conqüanto para alguns autores se situem no âmbito da Formação Corumbataí.

Além de estruturas similares às já aludidas com relação ao Teresina, mostram essas pedreiras estratificações dos tipos hummocky e sigmóide e estruturas de carga.

A estratificação cruzada do tipo sigmóide é interpretada por PETRI \& COIMBRA como hummocky, incipiente.

Fundamentando-se, grandemente, nas estruturas sedimentares detectadas, esses autores sugerem para o "Estrada Nova", um ambiente de planícies de maré associadas a lagunas, julgando difícil, duvidosa é, talvez, esporádica a ligação com o mar.

Possivelmente, trata-se de uma falha de expressão, pois seria inimaginável um ambiente dessa natureza sem conexão com o mar.

Supondo-se que o ambiente tenha sido efetivamente parálico, pareceram-nos muito lógica a interpretação dada às estruturas e o arranjo espacial das mesmas, conforme o pictograma apresentado por esses autores.

As estruturas biogênicas rotuladas como icnofósseis são de importância, também, para o nosso contexto. Elas vêm sendo estudadas por Vilma Campanha. Em parte, foram noticiadas no resumo apresentado por FÚLFARO et alii (1978). Sem entrar em pormenores, podemos informar que as até agora encontradas são todas próprias das zonas inframaré e intermarés.

\section{DADOS GEOQUÍMICOS}

Examinaremos agora os dados de valor paleoambiental obteníveis da Geoquímica.

GIOVANI et alii (1974) investigaram a variação dos valores de $\mathrm{C}^{13}$ e $018 \mathrm{em}$ amostras de carbonatos da Formação Irati. Constataram que as amostras procedentes do Rio Grande do Sul constituíam-se principalmente de carbonato de cálcio, enquanto as da porção setentrional da bacia correspondiam a dolomitos. Evolveu desse fato o problema da dolomitização, se primária, diage- 
nética ou supergênica. Esta última afastada pelos autores.

Os valores de $\delta \mathrm{C}^{13}$ obtidos nas amostras de dolomito discrepam muitíssimo dos padrões conhecidos para águas doces ou marinhas, sendo considerados anormais e resultantes de diagenêse. Ain$\mathrm{da}$, assim, os valores de $\delta \mathrm{O}^{18}$ nelas contidos foram os que se esperariam de lagos de água doce $(-2,6$ a $-8,2 \% 0)$.

As amostras do sul forneceram valores de $\delta \mathrm{C}^{13}$ entre $-2,6$ e $-7,6 \%$ de $\delta 0^{18}$ entre 6,7 e $-11,1 \%$, indicativos de precipitação em lago ou mar interno. Consideram-nos, os autores, representativos dos carbonatos primários do Irati.

No mesmo ano, SUGUIO et alii (1974) pesquisaram os teores de $\mathrm{C}^{13} \mathrm{e}$ de 018 em um calcário oolítico da Formação Corumbataí, obtendo valores elevados do primeiro $(1,93$ a $2,69 \% 0)$, fato indicativo de que o ambiente deposicional seria marinho ou lacustre de água salgada. Por outro lado, os teores de $0^{18}$ também se mostraram altos, quase alcançando $4,0 \%$ em uma das amostras. Isso denotaria um ambiente sujeito a evaporação intensa.

RODRIGUES \& QUADROS (1976) estudaram a composição mineralógica das argilas e o teor de boro do Grupo Passa Dois.

Como se sabe o boro é tido como um bom indicador de paleossalinidade. No caso do Irati, os teores de boro encontrados variaram de menos de 10 a $162 \mathrm{ppm}$. A distribuição geográfica desses valores, embora baseada em dados relativamente escassos, como advertem os autores, indica que a salinidade caía para oeste, sendo maior no centro e na borda oriental da bacia. Os teores de boro obtidos para o Serra Alta variaram entre 40 e 85 ppm, e para o Estrada Nova entre 30 e $364 \mathrm{ppm}$.

Esses valores são incompatíveis com um ambiente de água doce.

No mesmo ano, RAMOS \& FORMOSO (1976) estudaram os minerais de argila das rochas sedimentares da bacia do Paraná, chamando a atenção para a presença de corrensita no Grupo Passa Dois tendo em vista a sua presumida importância como indicador ambiental.

De acordo com os citados autores esse mineral de argila torna-se mais abundante nos calcários oolíticos do Teresina, embora ocorra, em menor proporção, no Serra Alta ena base do Rio do Rasto. Trata-se de um mineral ligado à clorita, mas, a sua formação, que se inicia na fase deposicional e prossegue através da diagênese, demanda um elevado teor de magnésio. Como nas águas doces o teor de magnésio é bem inferior ao dos mares, concluíram os autores que o paleoambiente do Teresina deve ter sido marinho.

Vejamos o que nos diz a Geoquímica da matéria orgânica.

TRIGUIS et alii (1982) constataram a existência de duas fácies orgânicas distintas no Irati. A fácies inferior caracterizar-se-ia pela predominância de matéria orgânica de origem continental e a superior pela predominância de matéria orgânica de origem marinha. Subentende-se que os autores consideram como marinha a matéria orgânica de origem algácea.

Com base na variação da espessura relativa dessas duas fácies, distinguiram três áreas dentro do âmbito da bacia, a saber: Área I, abrangendo o Estado de São Paulo e o norte do Estado do Paraná; Área II, abrangendo o sul do Estado do Paraná e o norte do Estado de Santa Catarina; Área III, correspondente ao sul do Estado de Santa Catarina e ao Estado do Rio Grande do Sul. Tal panorama faciológico levou os autores a conjecturar como possível causa dessa variação a interferência de paleobarreiras ligadas aos alinhamentos estruturais de direção NW-SE.

\section{MODELOS PALEOAMBIENTAIS}

Tivemos a oportunidade de considerar alguns dos modelos ambientais parciais, como o proposto por PETRI E COIMBRA (1982), ou de os discutir de passagem como no caso do apresentado por SCHNEIDER et alii (1974). Faltou, assim, um exame integral do segundo citado e nos propomos a fazê-lo agora de modo sucinto.

O modelo deposicional inferível do trabalho de SCHNEIDER et alii (1974) evolui de marinho a parálico, passando, depois, a fluvial.

Como já foi dito, esses autores dividem o Irati em dois membros: Taquaral e Assistência. Os lamitos do Taquaral corresponderiam a depósitos de ambien- 
te marinho de águas calmas, acamados abaixo do nível de base das ondas, enquanto o Assistência representaria um pacote de depósitos marinhos de águas rasas, sendo que os folhelhos betuminosos ter-se-iam gerado em áreas restritas da bacia e os carbonatos "em áreas de plataforma, como em São Paulo, onde condições de restrição mais severas originaram, inclusive, depósitos de rochas evaporíticas (anidrita)"'.

O ambiente inferido para o Serra Alta é similar ao do Taquaral.

Pelas suas características, os sedimentos da Formação Teresina documentariam a passagem de um ambiente marinho de águas relativamente profundas para um ambiente mais raso e agitado, dominado por marés, ou seja, para um ambiente de planície de maré.

De acordo com essa interpretação, o modelo deposicional do Teresina pressupõe uma planície de maré gigantesca, sem termo de comparação atual, em vista da extensão lateral atribuída à fácies em questão. Imagine-se um ciclo de maré nessa escala. Se a preamar começasse no sul teria que percorrer uns $1.500 \mathrm{~km}$ para alcançar o extremo norte da bacia uma vez que, segundo esses autores, o ambiente de planície de maré adentrava à Formação Corumbataí. Uma corrente de maré percorre, numa planície desse gênero, cerca de $24 \mathrm{~m}$ por minuto, de acordo com REINECK \& SINGH (1980).

O ideal seria que as fácies de planície de maré se restringissem a uma faixa estreita, estendida de norte a sul pela porção oriental da bacia e que gradassem para fácies mais profundas situadas na área central da sinéclise.

Os sedimentos do Serrinha corresponderiam, na opinião dos autores, a depósitos de planícies costeiras que progradaram sobre depósitos de planícies de maré. Representaria o Serrinha uma transição entre os sedimentos de águas rasas do Teresina e os depósitos fluviais do Morro Pelado.

Quanto à Formação Corumbataí, a sua parte inferior deveria ter-se gerado em ambiente marinho redutor, com tendência para águas cada vez mais rasas. A sua parte superior mostraria, entretanto, características de gênese em ambiente oxidante de águas rasas, com influência de marés.
Em síntese, o Passa Dois corresponderia a uma seqüência regressiva marinha sucedida, sem discordância, por uma sedimentação continental. O uso do termo marinho com relação aos ambientes deposicionais do Irati e Serra Alta parece ter sido muito liberal, pois os dados de qualquer sorte, disponíveis na época em que o modelo em discussão foi elaborado, não asseguravam essa atribuição, e nem os atuais.

Deve-se a GAMA JR. (1979) a concepção mais arrojada de modelo deposicional do Grupo Passa Dois, excluída a Formação Irati.

Com base nas características e no arranjo espacial das fácies distinguidas concluiu que estas se integravam em um complexo deltaico por ele denominado Sistema Deltaico Serra do Espigão.

Tal sistema ter-se-ia desenvolvido a partir de Mato Grosso, progradando por toda a bacia do Paraná, exceto nas regiões norte e nordeste do Estado de São Paulo e sul de Goiás, ocupadas pela chamada Planície de Maré Corumbataí. Os deltas progradantes assoreariam um imenso golfo aberto a sudeste.

O complexo deltaico compor-se-ia, essencialmente, das fácies Teresina, Serrinha e Morro Pelado, entendidas pelo autor como não circunstritas aos membros homônimos.

A fácies Teresina constituiria os depósitos prodeltaicos; a fácies Serrinha, os depósitos de frente deltaica; e a fácies Morro Pelado, os depósitos de planície deltaica subaérea. Teria o complexo progradado sobre sedimentos marinhos neríticos constituídos pela fácies Serra Alta. Quanto aos sedimentos da grande planície de maré, corresponderiam à fácies Corumbataí. Diga-se, de passagem, que a idéia da abertura do golfo a sudeste decorreu do exame do mapa de tendência de espessura da fácies Serra Alta. Mostra esse mapa que a isópaca zero distancia-se bastante para leste em relação aos limites atuais da bacia no setor sudeste.

Em linhas gerais, a hipótese pressupõe a existência de um conjunto de deltas destrutivos do tipo dominado por maré, progradando sob condições de clima quente e altamente pluvioso e farto suprimento de material detrítico. Eles teriam uma extensão de $500 \mathrm{~km}$ e a espessura total preservada dos seus depósitos alcançaria cerca de $1.000 \mathrm{~m}$. 
A hipótese sofreu restrições por parte de PETRI \& COIMBRA (1982). Para estes autores os lamitos escuros da fácies Serra Alta que Gama Jr. considera como depósitos de mar epicontinental, corresponderiam a sedimentos de uma bacia mais restrita, do tipo lagunar. Por outro lado, a presença comum de fendas de dessecação na fácies Teresina tornaria inviável interpretar o ambiente genético da mesma como prodeltaico.

Podemos acrescentar que nos pareceu estranha a ausência de vestígios de lutocinese, fenômeno muito comum nos deltas tanto marinhos como lacustres.

Segundo Gama Jr. (op.cit.) o depoeixo da associação das fácies Teresina e Serrinha não coincide bem com o depocentro da fácies Morro Pelado. Não conseguimos apreender a razão dessa assintonia, em se tratando de um sistema deposicional integrado.

A julgar-se pelos mapas de isópacas, a porção proximal do complexo deltaico corresponderia a área de maior subsidência da bacia. Aliás, a seção estratigráfica longitudinal desse complexo apresentada pelo autor comprova essa observação pois mostra que o pacote de sedimentos infra-Morro Pelado se adelgaça para SE, quando seria de se esperar o contrário, se fosse correta a hipótese do delta. Nesta consideração excluimos o Morro Pelado porque o seu topo é determinado por uma superfície de erosão.

De acordo com o modelo, o transporte deveria fazer-se segundo direções médias orientadas de noroeste para sudeste. BIGARELLA \& SALAMUNI (1967) mediram mais de mil inclinações de lâminas frontais de arenitos do Morro Pelado, desde o Uruguai até o Paraná, obtendo um padrão direcional algo diferente. No sul do Paraná e em Santa $\mathrm{Ca}-$ tarina, os dados de paleocorrentes concordam com as direções preconizadas no modelo, mas no norte do primeiro Estado mostram orientações dirigidas de norte para sul e no Estado do Rio Grande do Sul e no Uruguai, respectivamente, de sudoeste para nordeste e para noroeste.

Temos ainda um problema de escala: deltas de $500 \mathrm{~km}$ de extensão.

Finalmente, o modelo deltaico pressupõe o desenvolvimento sincrônico das fácies integrantes no decorrer da progradação. Em conseqüência, a fácies Serra
Alta acabaria sendo grandemente sincrônica com a fácies Morro Pelado e esta, praticamente por inteiro, com a fácies Teresina e Serrinha. Por outro lado, a fácies Corumbataí evoluiria, paralelamente, às quatro outras referidas. Em outras palavras, tal esquema invalida a referência do Morro Pelado ao Tatariano e do Estrada Nova ao Kazaniano, cronologia que tem sido seguida pelos geólogos com base nos fósseis e de perto pela radiometria.

\section{CONCLUSÕES}

A subdivisão estratigráfica do Grupo Passa Dois varia quase que de autor para autor e aquilo que um considera simplesmente como fácies ou litossoma outro trata como membro ou formação.

Os dados atualmente disponíveis ainda são insuficientes para a determinação precisa dos ambientes deposicionais. Mas a descoberta de lingulídeos e foraminíferos aglutinados na base do Irati do Estado de São Paulo permite assegurar que o ambiente deposicional dessa unidade manteve ligação com o mar. E as características da matriz, um folhelho escuro, indicam que esses organismos parecem suportar bem as condições anóxicas, a julgar pela sua presença no Mar Negro. Tanto eles como os foraminíferos associados são afeitos aos meios mixo-halinos.

Levando-se em consideração a presença de Botryococcus e evidências de outra ordem, a hipótese de um ambiente lagunar para o Irati, preconizada por muitos autores, afigura-se razoável.

Conquanto os siltitos do Serra Alta não reflitam condições tão anóxicas quanto os folhelhos do Irati s.s., a sua intima associação com estes, reconhecida por vários autores, faz supor que se geraram em ambiente similar. Com respeito aos níveis superiores do Passa Dois, que vêm sendo considerados parálicos com base nas estruturas sedimentares e nos dados geoquímicos, a única prova decisiva de que os seus ambientes deposicionais mantiveram uma ligação com o mar é de ordem paleontológica e consiste na presença de foraminíferos aglutinados na Formação Corumbataí.

Parece-nos uma ilação inquestionável a extensão dessa prerrogativa ao Estrada Nova. As estruturas sedimentares tanto 
da fácies Teresina como da parte superior do Corumbataí indicam, em conjunto, condições de águas rasas, com o fundo ao alcance das ondas e freqüente exposição subaérea dos depósitos. Algumas intercalações de sedimentos maciços nas seqüências em apreço poderiam, entretanto, sugerir fases de deposição abaixo do nível de base das ondas.

Supor-se uma bacia com franco domínio marinho seria, contudo, negligenciar os parâmetros biológicos, pois os conchostráceos e as carófitas profusamente distribuídos nessas seqüências, não tolerariam condições de vida com salinidade muito próxima da dos mares. E o endemismo da malacofauna também não corroboraria aquela suposição.

Sem perder de vista o risco que se corre ao especular sobre a natureza de um paleoambiente numa situação, como esta, de escassez de dados, julgamos aceitável a hipótese de uma planície de maré para a fácies Teresina. Induzem-nos a isso as estruturas sedimentares presentes nessa fácies combinadas com os dados paleontológicos. Note-se que falamos em fácies e não na formação homônima, pois se confundirmos as duas coisas estaremos dando uma amplitude descomunal ao ambiente.

Sendo problemático preencher a bacia inteira com uma única fácies de planície de maré, teríamos que apelar para uma combinação de fácies. Talvez, um ambiente lagunar, com fácies satélites de planícies de maré possa ser a solução. A fácies Serra Alta ajudaria no caso, conquanto essa suposição fira os cânones atuais.

Naturalmente, essa solução além de ser muito hipotética é também muito simplista, pois, admitindo-se um sistema de lagunas associadas com planícies de maré, estar-se-ia predispondo a vasta bacia a outras modalidades de ambientes normalmente conjugados, como o estuarino, por exemplo.

Onde estariam as fácies marinhas? Gradaria tal complexo deposicional para o ambiente fluvial do Morro Pelado sem uma fase lacustre intermediária? São outras questões que ficarão aguardando resposta.

Os sedimentos do Grupo Passa Dois correspondem, predominantemente, a clásticos finos e carbonatos, fato sugestivo de uma subsidência lenta, talvez combinada com uma situação de topografia muito aplainada. Assim é dado imaginar que a sinéclise que acolheu esses sedimentos encastroava-se em uma plataforma baixa, extremamente arrasada pela erosão. Tais condições predisporiam os depósitos a um recobrimento expansivo da área extra-bacial. Se isso de fato ocorreu, essas expansões foram, posteriormente, destruídas pela erosão, que também pode ter removido os tratos de fácies marinhas. E, quem sabe, parte deles se preservou na plataforma continental atlântica, como suspeitam alguns autores.

Ao finalizar este artigo, queremos ressaltar que a nossa intenção foi mais a de procurar demonstrar a complexidade do assunto do que oferecer soluções. Concordamos, entretanto, com os que consideram que um bom entendimento dos paleoambientes só poderá ser alcançado sob a óptica de uma estratigrafia mais realista que considere fácies ou litossomas como tais e não como membros ou formações.

\section{AGRADECIMENTOS}

O presente trabalho foi lido criticamente pelos colegas Setembrino Petri e Vilma Alves Campanha aos quais agradecemos as valiosas sugestões apresentadas.

\section{REFERỀNCIAS BIBLIOGRÁFICAS}

ADAMS, J.E. \& FRENZEL, H.N. 1950 Capitan barrier reef, Texas and New Mexico. The Journal of Geology, Chicago, 111., 58 (4):289-312, Jul.

ANDREIS, R.R. et alii 1980 O Grupo Rosário do Sul (Triássico) no Rio Grande do Sul, Brasil
In: CONGRESSO BRASILEIRO DE GEOLOGIA, 31. ${ }^{\circ}$, Balneário de Camboriú, SC, 1980. Anais. São Paulo, Sociedade Brasileira de Geologia. v.2 p.659-673.

ASSERETO, R.L.A.M. \& KENDAL, C.G.St.C. 1977 Nature, origin and classification of pe- 
ritidal tepee structures and related breccias. Sedim entology, Amsterdam, 24(1/3): 153-210.

BARBERENA, M.C. et alii 1980 Contribuição à estratigrafia e bioestratigrafia do Grupo Passa Dois na serra do Cadeado (Nordeste do Paraná), Brasil. Revista Brasileira de Geociências, São Paulo, 10(4):268-275.

1983 The present state of the knowledge on the Permian and Triassic tetrapods of southern Brasil. In: CONGRESSO BRASILEIRO DE PALEONTOLOGIA, $8 .^{\circ}$, Rio de Janeiro, 1983. Resumo das comunicações. Rio de Janeiro, Sociedade Brasileira de Paleontologia. p. 8

BIGARELLA, J.J. \& SALAMUNI, R. 1967 Some paleogeographic and paleotectonic features of the Paraná basin. In: SIMPÓSIO INTERNACIONAL DE ESTRATIGRAFIA E PALEONTOLOGIA DO GONDWANA, $1 .^{\circ}$. Curitiba, 1967. Problems in Brazilian Gondwana geology, edited by J.J. Bigarella, R.D. Becker and I.D. Pinto. Curitiba, Instituto de Geologia, Universidade Federal do Paraná. p.235-301.

BORTOLUZZI, C.A. 1974 Contribuição à geologia da Formação Santa Maria, Rio Grande do Sul, Brasil. Pesquisas, Porto Alegre, 4(1):7-86.

BRITO, I.M. 1982 Estratigrafia da Bacia do Paraná III: O Grupo Passa Dois. Anais da Academia Brasileira de Ciências, Rio de Janeiro, 54(2):460-461.

CAMPANHA, V.A. 1984 Ocorrência de braquiópodes inarticulados na Formação Irati, no Estado de São Paulo. Comunic. sessão Acad. Bras. Ciênc. 14-8-1984.

EYSINGA, F.W.B. van 1978 Geological time table. 3rd. Edition. Amsterdam, Elsevier.

FÚLFARO, V.J. et alii 1978 Considerações sobre a gênese da Formação Estrada Nova (P) da bacia do Paraná. In: CONGRESSO BRASILEIRO DE GEOLOGIA, 30. ${ }^{\circ}$, Recife, 1978. Resumos das comunicações. Recife, Sociedade Brasileira de Geologia. Núcleo Nordeste. p. 158 (Boletim n. ${ }^{\circ} 1$ )

GAMA JR. E.G., 1979 A sedimentação do Grupo Passa Dois (exclusive Formaçâo Irati): um modelo geomórfico. Revista Brasileira de Geociências, São Paulo, 9(1):1-16.

GAMERMANN, N. 1973 Formação Rosário do Sul. Pesquisas, Porto Alegre, 2:5-35.

GIOVANI, W.F. de et alli 1974 Unusual isotopic composition of carbonats from Irati Formation, Brazil. Geological Society of America Bulletin, Boulder, Col., 85(1):41-44.

HARMS, J.C. et alii 1975 Depositional environments as interpreted from primary sedimen- tary structures and stratification sequences. Tulsa, Oklahoma, Society of Economic Paleontologists and Mineralogists. 161p. (Short Course, lecture notes, 2)

LANDIM, P.M.B. \& FÚLFARO, V.J. 1972 Trend-surface analysis of carboniferous and Permian thickness data from Paraná basin. Anais da Academia Brasileira de Ciências, Rio de Janeiro, 44:187-196, Supl.

MEZZALIRA, S. 1971 Contribuição ao conhecimento da geologia de subsuperfície e da paleontologia da Formação Irati no Estado de São Paulo. Anais da Academia Brasileira de Ciências, Rio de Janeiro, 43:273-336, Supl.

et alli 1981 Léxico estratigráfico do Estado de São Paulo. São Paulo, Instituto Geológico. 161. (Boletim, 5)

PETRI, S. \& COIMBRA, A.M. 1982 Estruturas sedimentares das formações Irati e Estrada Nova (Permiano) e sua contribuição para elucidação dos seus paleoambientes geradores, Brasil. In: CONGRESSO LATINO AMERICANO DE GEOLOGIA, 5., Argentina, 1982. Actas. Buenos Aires, Asociacion Paleontologica Argentina. v.2 p.353371.

\& FÚLFARO, V.J. 1983 Geologia do Brasil (Fanerozóico) São Paulo, T.A. Queiroz, Ed. da Universidade de São Paulo. 631p. (Biblioteca de Ciências naturais, v.9)

RAMOS, A. \& FORMOSO, M.L.L. 1976 Clay mineralogy of sedimentary rocks of the Paraná basin, Brasil. Revista Brasileira de Geociências, São Paulo, 6(1):15-42.

REINECK, H. \& SINGH. I.B. 1980 Depositional sedimentary environments. Berlin, SpringerVerlag. 549p.

RODRIGUES, R. \& QUADROS, L.P. 1976 Mineralogia das argilas e teor de boro das formações paleozóicas da Bacia do Paraná. In: CONGRESSO BRASILEIRO DE GEOLOGIA, 29..$^{\circ}$ Ouro Preto, 1976. Anais São Paulo, Sociedade Brasileira de Geologia. v.2 p.351-379.

SCHNEIDER, R.L. et alii 1974 Revisão estratigráfica da Bacia do Paraná. In: CONGRESSO BRASILEIRO DE GEOLOGIA, $28^{\circ}$, Porto Alegre, 1974. Anais. São Paulo, Sociedade Brasileira de Geologia v.1 p.41-65.

SUGUIO, K. et alii 1974 Calcários Coliticos de Taguai (SP) e seu possivel significado paleoambiental na deposição da Formação Estrada Nova. Revista Brasileira de Geociências, 4(3): 142-166.

TRIGUIS, J.A. et alii 1982 Fácies orgânicas da Formação Irati. In: CONGRESSO BRASILEIRO DE PETRÓLEO, $2 .^{\circ}$.(no prelo) 